\title{
Editorial Material: Developing the potential of social media in cardiovascular care
}

\author{
Tiny Jaarsma
}

\section{Linköping University Post Print}

\section{Tweet}

N.B.: When citing this work, cite the original article.

Original Publication:

Tiny Jaarsma , Editorial Material: Developing the potential of social media in cardiovascular care, 2014, European Journal of Cardiovascular Nursing, (13), 5, 386-387.

http://dx.doi.org/10.1177/1474515114550458

Copyright: Elsevier / SAGE Publications (UK and US): 12 month Embargo http://www.uk.sagepub.com/home.nav

Postprint available at: Linköping University Electronic Press

http://urn.kb.se/resolve?urn=urn:nbn:se:liu:diva-111748 
Developing the potential of social media in cardiovascular care editorial

Tiny Jaarsma

Health care providers seem slow to embrace social media in patient care. It seems like we try to do our best to stay novel and innovative and several novel interventions have been developed and tested in the last few decades. For example, recent papers in the European Journal of Cardiovascular Nursing discuss the use of motivational interviewing to improve cardiovascular health (1), present the development of computer-based educational programs for patients with congenital heart disease, and describe how to use the Internet in secondary prevention (2,3). Another example of a rather 'new' intervention is exergaming for patients, which is described in a paper presented in the current issue of the European Journal of Cardiovascular Nursing (4).

Social media, propelled by mobile technology, is increasingly used to change people's behavior. Social media refers to the means of interaction among people, where they create, share, and/or exchange information and ideas in virtual communities and networks, such as Facebook, Twitter or YouTube. The increasing role of social media in patient care was recently presented in a report by the IMS Institute for Healthcare Informatics (5), which states that Facebook is the fourth most popular source of health information in the United Kingdom. In the US, specific diseases receive the most interest in health care-related social media, followed by lifestyle changes, health insurance details and safety information (5). In Canada, 70\% of citizens use the Internet for health-related information, and $92 \%$ of these use the search engine Google to gather this information rather than a health portal (5). People seeking information are more likely to turn to conventional digital sources, while those in need of emotional support will be more drawn to social media platforms (5).

Social relationships are known to affect health and quality of life through behavioral, psychosocial, and physiological pathways $(6,7)$, and social media might have similar effects. Social media can empower patients and make them more informed (and maybe more demanding). Social networks can influence health through numerous pathways, such as 
emotional support (sharing experiences), instrumental support (financial or practical), informational support, or appraisal (decision-making) support (8). Current social media provides tips for staying healthy, motivates people to stay healthy, connects physical activity partners, reports personal experiences, and gives an opportunity to ask questions and receive direct feedback from others living with the same disease. Social media-based health promotion interventions are promising since it is known that social networks can be critical in shaping young people's eating behaviors and body weight, and vice versa (8). In addition, Facebook or Twitter are used to recruit participants for trials, channel information or disseminate knowledge.

At this point, the greatest challenge for health care professionals is to implement these new developments in a timely manner, but at the same time make evidence-based decisions on how to use social media in patient care, for example in prevention programs. Social media or Internet interventions hold a significant promise for application in the research setting as they are relatively inexpensive to scale up for broad implementation and they can facilitate data collection. Using social media gives health care professionals room to use a new kind of intervention, serving current and future health care users. Furthermore, maybe it can help reach groups of patients that are otherwise not reached. Social media interventions can be adapted quickly and are easily tailored to patient needs.

It is questionable how ready healthcare providers are for digitally demanding patients (5). In a study on patients' and health care providers' views and expectations of social media, the health care providers expressed that the main barriers for using social media in their practice include their perception of social media as being inefficient, the fact that they do not receive compensation for the health care they provide via social media, their lack of skills, and legal or privacy concerns (9).

The patients in that study expressed concerns about using social media for health care because they did not feel at ease giving personal information via social media and did not want to be known as a patient on the Internet. They were also worried about the reliability of the information presented in social media. (9) Other issues that merit awareness include problems such as cyberbullying, addiction and resultant sleep deprivation (5). Other sensitive issues 
include confidentiality in the communication between health care providers and professionals on social media.

To conclude, we live in interesting times, and there are a lot of benefits and challenges in connection with the integration of social media in current health care practice. With proper design and evaluation we can use social media in patient care, thus creating a wealth of possibilities to increase participation, boost motivation, give social support, provide information and disseminate knowledge to a large audience.

References

1. Ski CF, Thompson DR. Motivational interviewing as a brief intervention to improve cardiovascular health. Eur J Cardiovasc Nurs 2013 Jun;12(3):226-9.

2. Rönning H, Nielsen NE, Strömberg A, Thilen U, Swahn E. Development and evaluation of a computer-based educational program for adults with congenitally malformed hearts. Eur J Cardiovasc Nurs 2013 Feb;12(1):78-86.

3. Neubeck L1, Ascanio R, Bauman A, Briffa T, Clark AM, Freedman B, Redfern J. Planning locally relevant Internet programs for secondary prevention of cardiovascular disease. Eur J Cardiovasc Nurs 2011 Dec;10(4):213-20.

4. Verheijden Klompstra L, Jaarsma T, Strömberg A. Exergaming in older adults: A scoping review and implementation potential for patients with heart failure. Eur J Cardiovasc Nurs. 2014 (this issue)

5. IMS Institute for Healthcare Informatics. Engaging patients through social media. Is healthcare ready for empowered and digitally demanding patients? January 2014. Parsippany, USA.

6. Umberson D, Montez JK. Social Relationships and Health: A Flashpoint for Health Policy. J Health Soc Behav. 2010; 51(Suppl): S54-S66.

7. Årestedt K, Saveman BI, Johansson P, Blomqvist K. Social support and its association with health-related quality of life among older patients with chronic heart failure. Eur J Cardiovasc Nurs. 2013 Feb;12(1):69-7) .

8. Li JS, Barnett TA, Goodman E, Wasserman RC, Kemper AR. Approaches to the Prevention and Management of Childhood Obesity: The Role of Social Networks and the Use of Social Media and Related Electronic Technologies: A Scientific Statement From the American Heart Association. Circulation. 2013;127:260-267.

9. Antheunis, ML, Tates K, Nieboer T. Patients' and health professionals' use of social media in health care: Motives, barriers and expectations. Patient Education and Counseling 2013: 92; 426-431. 
